\title{
Identifying Occupant Patterns in a Super-tall Building Through the Theory of Planned Behavior Model.
}

\author{
Case study: Jin Mao tower Lujiazui, Shanghai - China
}

\author{
Dr. Limin Ma Professor \\ College of Environment Science \& Engineering Tongji \\ University \\ The State key laboratory of Pollution Control \& \\ Resource Reuse \\ Shanghai, 1239 Siping road, 200092 P.R. China \\ E-mail: lmma@tongji.edu.cn
}

WWF Programme manager Wang Qian

WWF Shanghai Programme Office

Shanghai, Garden Lane 121\# North Zhongshan, 200083

P.R. China

E-mail: wangqian@wwfchina.org

\author{
Architect Nataly Arévalo \\ College of Environment Science \& Engineering, Tongji \\ University \\ UNEP - Tongji Institute of Environment and \\ Sustainable Development \\ Shanghai 1239, Siping road, 200092 P.R. China \\ E-mail: natalyarch@hotmail.com
}

\begin{abstract}
Substantial energy, water, and solid waste savings can be achieved by user behavior detection and consumption patterns. This empirical research proposes a systematic framework with the adoption of mixed methods approach. Qualitative data is based on the Theory of Planned Behavior model (TPB), which analyses personal and situational variables detecting the consumption awareness of the building occupant, as the first research objective. This research aims to provide new management to promote a positive and sustainable behavior shift. A survey was conducted to provide an "ultimate status" of the building user behavior. The survey method is considered most adequate for the building user due to the direct contact with preferences and habits. Inclusion criteria focused on men and women FTW (full time workers) in the super-tall building. Finally, the results were computed, measured, and analyzed by Statistical Package for the Social Sciences (SPSS). The findings demonstrate the type and frecuency of plugging personal appliances, the building water consumption above baselines levels, the most generated solid waste in the building, and the enviornmental and consumption awareness of the user. Moreover it was possible to understand and rank the building user's behaviors, preferences, and awareness that could modify the building consumption. Under the conclusion section it was proposed new potential strategies to be developed further as pilot projects in super-tall buildings.
\end{abstract}

Keywords-component; super-tall building, behavior, occupant patterns

\section{INTRODUCTION}

The development of high-rise buildings in Chinese cities has climaxed in recent decades [1]. High density buildings positively affect mixed land use, increasing connectivity, improve walkability, reduce footprint reduction, enhance social interaction, and improve quality of life [2]. Modern high-rise buildings tend to influence in social, economic and cultural aspects. Among them, the cultural and social factors have a particularly means for high-rise building and the community[1].

Global patterns demonstrate energy abundance as a basic foundations of modern civilizations. Since the middle of the twentieth century, consumption, production, and global energy use has increased massively [3]. The building sector contributes up to $30 \%$ of global annual greenhouse gas emissions and consumes up to $40 \%$ of all energy [4]. The United Nations Environment Program UNEP mentions five major policy targets: the increase of energy efficiency of new \& existing buildings, the increase of appliance's efficiency, the encouragement of energy and distribution companies to support emission reductions in the building sector, the substitution of fossil fuels with renewable energies, the change and improvement of attitudes and behavior [4].

Retrofitting existing buildings to operate at an optimal level is an energy saving priority according to Sylvie Lemmet Director of the Division of Technology, Industry and Economics at UNEP. There is tremendous scope for using this opportunity to update building systems in concordance with their building occupants. As reported by Carbon Trust, the estimation of energy costs could be reduced by $10-20 \%$ through simple actions with no or little capital costs, and the amount of energy saved via behavioral changes can be as high as $100 \%$ [5]. A review of the literature revealed that there is a lack of practical 
tools and approaches to assess how well an organization is doing in managing or changing, building systems use and occupants behavior [5]. Changing behavior can reduce building energy resulting in reduced $\mathrm{CO} 2$ emissions. [6] Coleman emphasizes that behavior is a complex combination of emotions, morals, habits, social and normative factors, which can be divided into internal factors (beliefs, attitudes, values); and external (institutions, regulations, social contexts); and habits or routine factors. On the next part it will be explain the theory applied for understanding the building social behavior.

\section{THEORY OF PlAN BEHAVIOUR}

\section{A. Buildings and Occupant behaviour}

Energy saving technologies are affected by the behavior of human beings [7]. Theory of Planned Behavior is an effective model that relates building consumption and user behavior. The interesting part of this research is the application of a social-cognitive model to one of the most technologically advance super-tall buildings in Shanghai, China. This theory also bases its principals in Environmental Psychology [8] and decision-making process.

\section{B. Planned Behavior Model}

Sociology studies argue that social variables strongly depend on subjective interpretation. Problematic situations or specific scenarios exist primarily in terms of how they are defined and conceived by society [9]. Societal problem situations are mitigated through societal transformations meaning that societies must undergo fundamental changes in specific domains [9], to reduce the building energy consumption, individuals must understand specific settings and mitigate diverse habits or behavior.

The Theory of Planned Behavior (TPB) predicts and explains human behavior in specific contexts [10]. TPB emphasizes that human behaviors are governed not only by personal attitudes, but also by social pressures and a sense of control [10]. It is stated that the TPB is determined by individual and personal intentions and habits. Human behavior comes as the comprehensive results of knowledge, attitudes, needs, incentives, and peer pressures [7]. Four major interrelated types of causal variables can be linked to environmentally significant behavior as part of this model:

- Attitudinal factors: personal beliefs, values, attitudes or norms.

- External or contextual factors: incentives and costs (e.g. monetary incentives/ costs, physical difficulties of specific actions), regulations, or community expectations.

- Personal capabilities: knowledge and skills required for a particular action, or the availability of time to act. Socio-demographic variables such as age, education, or income may be indicators of personal capabilities.

- Causal variables: routine or habit. [5]

\section{Features of Behavioral Energy Saving Model}

Behavior energy-saving studios in China are relatively scarce and many of the research is solely descriptive [7]. Other studios focus on phenomena of household energy usage. Omitting super-tall buildings a more energy consumptive area. Behavior energy-saving is a feasible opportunity to reach the building end user without a considerable amount of investment. The main tasks for the building owner, operator, and managers are the identification of user weaknesses, the enhancement of knowledge, and engagement of the building user.

\section{RESEARCH METHODOLOGY}

Based on the review of existing literature it is proposed a framework based on the theory of planned behavior model (TPB) that analyses personal \& situational variables in terms of electricity, water consumption and solid waste generation.

A survey will be implemented to develop and test the conceptual model. The survey sample criteria include: men and women FTW (full time workers) in the super-tall building, with middle - higher educational level and, those who voluntarily want to participate in the research (they will sign an agreement form to be part of the research). The chosen behaviors were specific to those that generate more influence in the energy consumption, water consumption, and solid waste generation; that the operators cannot control. Findings were formulated by the Statistical Package for the Social Sciences (SPSS).

\section{RESULTS}

The Statistical analysis on the demographic data has shown that the average age of respondents is 26 with a range age between 19 and 50 years old. The data exhibits equal gender distribution and most of the respondents fall under single marital status. More than half of respondents live with their families and their workplace is located between 1 and 50 floors representing job duties including: office boss, sales man, building security personnel, office administrator, and office attendant. After data calculated with statistical software SPSS the results obtained for energy, water and solid waste consumption and awareness were the following:

\section{A. Energy Consumption}

In correlation between the first and the second question from the survey about "Which type of electric appliances from your ownership you plug into your office outlets?" and "For how many hours do you plug your electric appliances into the office outlets" the findings provide a clear statement that most of the building users are connecting their personal appliances such as mobile phone chargers and laptops to the building outlets for the period of 1 to 4 hours. This user behavior determines that exist constantly an extra energetic charge in the energy building systems.

\section{B. Water Consumption}

The following findings have a correlation between the genre and the number of big flush (solid waste) and small flush (liquid waste) performed during a working day. These questions were based on Leadership in Energy and Environmental Design LEED baselines, which states women average 3 dual flush bathroom trips per day ( 1 big flush, 2 small flush), while men have 3 bathroom trips (1 water closet trip, 2 urinal trips) [11]. The importance of these finding are necessary to compare with the building operator to estimate the correct total water consumption. 
So as displayed on the questionaries' survey results more than $50 \%$ of women visit the bathroom for a small flush for 3 times per day and 1 time per big flush. On the other hand, more than $50 \%$ of men visit the bathroom for a small flush 3 times and 1 time for a big flush during working hours. This findings show that women and men perform 1 more small flush (liquid waste) than building baselines. The next correlation is between water bottle dispenser usage and the number of floors used. Results shown that more crowded and public open levels are changing water bottles 4 times more than a normal office.

The feedback obtained on this category demonstrates the difference between the building baseline and the toilet facility daily usage. The possibility to find reductions on the water bottle dispenser usage without interrupting the user comfort it is necessary.

\section{Solid waste generation}

The solid waste findings show that the majority of the building waste comes from paper and plastic. This waste generation was found in bigger amount in commercial areas over regular offices. According to the building users and the findings they perceived as they are depositing the recyclable waste in the right recycling trash bin as a "very often state". It is important also to note that $10 \%$ of respondents "never" deposit the solid waste in the proper

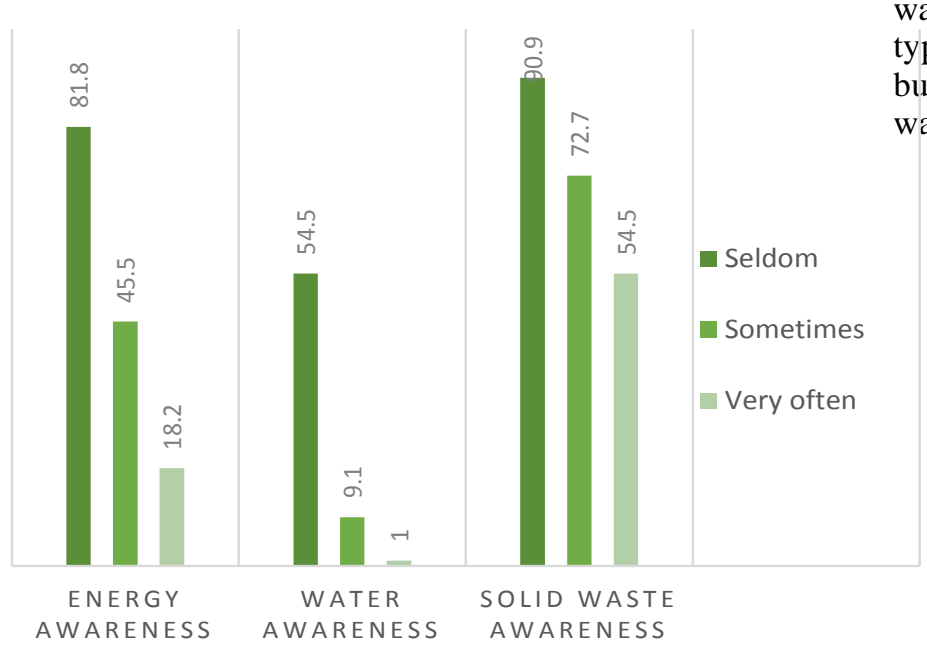

Figure 1. Building user awareness and energy, water and solid waste

trash bins. The higher education one has, the more aware one is of correct solid waste disposal with more than $50 \%$. It is presumable that if the majority of solid waste comes from paper and plastic, there are enormous possibilities to obtain revenue out of it. Building user awareness needs to be given by the building personnel.

\section{Energy, water, solid waste consumption and generation awareness}

One of the main research objectives were to understand the current level of building user awareness in terms of energy, water and solid waste consumption and generation (Fig .1). To analyze the relationship between awareness variables in SPSS software, it was elected the frequency tool that directs the research to three main building user's choices: seldom, sometimes, and very often. Findings showed an elevated number of respondents with "seldom" response towards their saving energy awareness (81.8\%), while half of the users with $(54.5 \%)$ claimed their saving water intentions in office toilet facilities, and $(90.9 \%)$ of respondents rarely have a willingness to allocate their own solid waste in the right trash bin. Moreover, it is important to mention that the entire scale used for these questions was always, very often, sometimes, seldom, never. In addition, $54.5 \%$ of building users correspond to the highest level of education "University". This variable is significant because of the close relationship between education - and environmental awareness.

\section{E. Summary of results}

In short, there is a considerable increase in electrical demand due to plug loads from personal laptops and mobile phone chargers. This action contributes to the increase of electricity expenditures throughout the year. The gap between user water consumption and building baselines levels shows the importance of user control. For instance, building users showed that they perform one more small flush than the baselines, creating a contradiction with the initial estimations. Regarding solid waste, there is a great potential for building managers to develop strategies to enhance user behavior towards solid waste generation reduction. Paper and plastic are the main type of solid waste to be recycled in Jin Mao super-tall building, therefore the enormous possibility to re-use this waste either at building or city level.

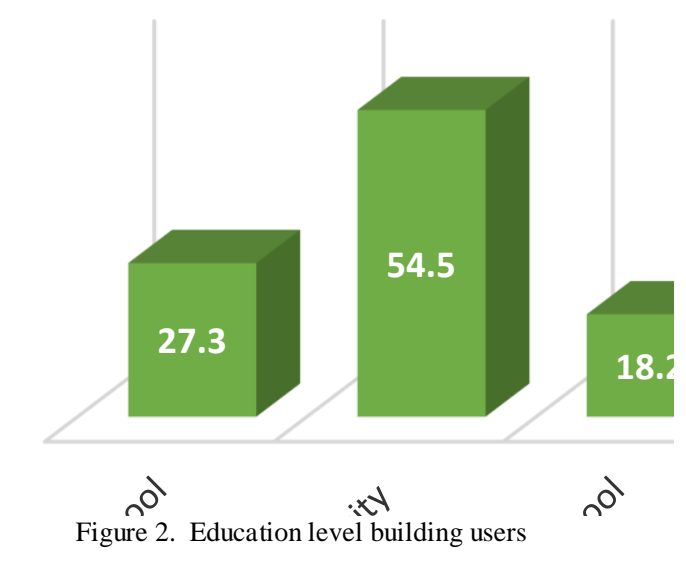

\section{DISCUSSION}

Education is highlighted on this research as a key saving strategy. As the statistical results showed half of participants $(54.5 \%)$ have high education and the rest it is assumed that have no knowledge of environmental awareness. This assumption is based on Cui Li on "The Influence of Human's Behavior on Energy-Efficient Technologies Promotion in China" study [7]. Cui Li states that "the never energy concerned group" where the ones with no energy-efficient knowledge. 


\section{CONCLUSIONS}

Theory of Planned Behavior model (TPB) provided the possibility to detect patterns and specific behaviors that may modified the building consumption readings. The results obtained are useful to design better incentives (or other regulator mechanisms) for load shaping, and new building policies that can be tailored to the characteristics of building users in Jin Mao tower. Suggested strategies for building managers and operators are to provide building user energy, water and solid waste savings tips and conduct regular energy audits. Education and information should be a priority for building users so they can start the decision-making process. This process starts when the user realizes the problem, accepts the reality, and wants to change behavior. These preconditions to take action may be enhanced if the person receives additional encouragement such as social, economic, and personal rewards. The importance of receiving feedback from the building user is extremely important since it can help to find data that can bring new consumption and generation targets. Further, the need to increase the building user awareness, can be implemented through a "raising awareness campaign" at the building level, as a starting point. The management should develop an effective communication platform such as a meeting and on-line feedback system, involving all key participants related to maintenance activities. City level involvement would have a significant impact as well.

\section{ACKNOWLEDGMENT}

The research has been possible thanks to the collaboration of WWF Programme manager Wang Qian from WWF - China. This work was financially supported by MOST 863 Program of China (2012AA063608) \& Chinese NSF (21377098), Foundation (2014ZX07405003). We also thank the two reviewers and the associate editor for their comments, which improved the manuscript.

\section{REFERENCES}

[1] P. Feng and W. Xingkuan, "Sustainable development of high-rise building," Procedia Eng., vol. 21, pp. 943-947, 2011.

[2] R. Bardhan, K. Kurisu, and K. Hanaki, "Does compact urban forms relate to good quality of life in high density cities of India ? Case of Kolkata," vol. 48, pp. 55-65, 2015.

[3] M. otto Müller, Diffusion Dynamics of Energy-Efficient Renovations, vol. 14. 2013.

[4] UNEP, "Buildings and climate change: a summary for decisionmakers," United Nations Environ. Program. Sustain. Build. Clim. Initiat., pp. 1-62, 2009.

[5] M. Ucci, T. Domenech, a. Ball, T. Whitley, C. Wright, D. Mason, K. Corrin, a. Milligan, a. Rogers, D. Fitzsimons, C. Gaggero, and a. Westaway, "Behaviour change potential for energy saving in non-domestic buildings: Development and pilot-testing of a benchmarking tool," Build. Serv. Eng. Res. Technol., vol. 35, pp. 36-52, 2012.

[6] M. J. Coleman, K. N. Irvine, M. Lemon, and L. Shao, "Promoting behaviour change through personalized energy feedback in offices,” Build. Res. Inf., vol. 41, no. July 2015, pp. 637-651, 2013.

[7] C. Li, Z. Li, W. Yao, and Y. Wang, "Proceedings of the 8th International Symposium on Heating, Ventilation and Air Conditioning," vol. 263, pp. 581-591, 2014.

[8] C. Fischer, "Feedback on household electricity consumption: a tool for saving energy?," Energy Effic., vol. 1, no. 1, pp. 79-104, 2008.

[9] M. Ucci, "Sustainable buildings, pro-environmental behaviour and building occupants: A challenge or an opportunity?,’ J. Retail Leis. Prop., vol. 9, no. 3, pp. 175-178, 2010.

[10] G. Energy, Zero-Carbon Energy Kyoto 2012. 2013.

[11] "LEED Green Associate Study Guide ( LEED v4 ) Table of Contents," 2014. 